DE

M E D I C I N A

T R O P I C A L

$\mathrm{DE}$

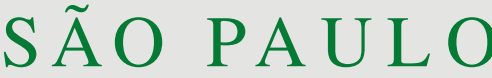

JOURNAL OF THE SÃO PAULO INSTITUTE OF TROPICAL MEDICINE

${ }^{1}$ Universidade Federal do Estado do Rio de Janeiro, Serviço de Clínica Médica, $10^{\mathrm{a}}$ Enfermaria, Rio de Janeiro, Rio de Janeiro, Brazil

${ }^{2}$ Fundação Oswaldo Cruz, Laboratório de AIDS e Imunologia, Rio de Janeiro, Rio de Janeiro, Brazil

${ }^{3}$ Universidade Federal do Estado do Rio de Janeiro, Centro de Ciências Biológicas e da Saúde, Rio de Janeiro, Rio de Janeiro, Brazil

${ }^{4}$ Hospital Universitário Gaffrée e Guinle, Laboratório de Imunologia, Rio de Janeiro, Rio de Janeiro, Brazil

Correspondence to: Guilherme Almeida Rosa da Silva

Universidade Federal do Estado do Rio de Janeiro, Serviço de Clínica Médica, $10^{a}$ Enfermaria, Rua Mariz e Barros, 775, CEP 22290-240, Rio de Janeiro, RJ, Brazil

E-mail: drguialmeida@gmail.com

Received: 12 July 2018

Accepted: 21 September 2018

\section{Chlamydia trachomatis asymptomatic urethritis recurrence among males living with HIV-1}

\author{
Guilherme Almeida Rosa da Silva ${ }^{1,2}$, Heloisa Loureiro de Sá Neves Motta', \\ Erik Friedrich Alex de Souza', Pedro Afonso Nogueira Moises Cardoso', \\ José Henrique Pilotto², Walter Araujo Eyer-Silva ${ }^{3}$, Luiz Cláudio Pereira \\ Ribeiro ${ }^{4}$, Mônica Soares dos Santos ${ }^{4}$, Marcelo Costa Velho Mendes de \\ Azevedo', Jorge Francisco da Cunha Pinto', Rogerio Neves Motta1, \\ Fernando Raphael de Almeida Ferry ${ }^{1}$
}

\section{ABSTRACT}

A prevalence of $3.47 \%$ of asymptomatic Chlamydia trachomatis urethritis has been previously reported among males living with HIV infection in Brazil. This study aims to assess the recurrence of $C$. trachomatis urethritis three years later in the same cohort of patients and analyze associated risk factors. A total of 115 male patients diagnosed with HIV infection, with no symptoms of urethritis and observed since May of 2015 in followup visits were enrolled. They had urine samplers tested by PCR for C. trachomatis and $N$. gonorrhoeae between February and March 2018. Results: Three of the four patients who had asymptomatic $C$. trachomatis urethritis three years before were recurrently positive for $C$. trachomatis urethritis. Two new patients were diagnosed as positives, accounting for a total asymptomatic $C$. trachomatis urethritis prevalence of $4.34 \%$. The prevalence during the whole study was $5.21 \%$. The relative risk for a new urethritis episode among those previously diagnosed with urethritis is $\mathrm{RR}=41.62$ (95\% CI: 9.42-183.84), $\mathrm{p}<0.01$. Patients who presented asymptomatic urethritis anytime and who were recurrently positive for $C$. trachomatis had a lower mean age $(\mathrm{p}<0.01)$. Married individuals were protected regarding asymptomatic urethritis $[\mathrm{p}<0.01, \mathrm{OR}=0.04(0.005-0.4)]$ and had lower risk to develop recurrence $[\mathrm{p}<0.01, \mathrm{RR}=0.86(0.74-0.99)]$. Illicit drugs users had risk associated to asymptomatic urethritis $[\mathrm{p}=0.02, \mathrm{OR}=5.9(1.03-34)]$ and higher risk to develop recurrence $[\mathrm{p}<0.01, \mathrm{RR}=1.1$ (1-1.22)]. Conclusion: The recurrence of asymptomatic $C$. trachomatis urethritis after treatment among males living with HIV infection in Brazil can be considered high and should not be neglected.

KEYWORDS: HIV. AIDS. Urethritis, Chlamydia trachomatis. Neisseria gonorrhoeae.

\section{INTRODUCTION}

A prevalence of $3.47 \%$ has been previously reported for asymptomatic urethritis among males living with HIV infection, treated in a large reference center for HIV infection in Brazil. All cases were caused by Chlamydia trachomatis ${ }^{1}$. These data were compared with studies in the general population without HIV infection, which report a prevalence of asymptomatic urethritis of 5\% in military Brazilian men and also with other similar studies in the United States that presented prevalences of $1.5 \%, 3.7 \%$ and $5.7 \%{ }^{2-5}$. Studies on asymptomatic urethritis specifically in male populations living with HIV are scarce, but the prevalences reported were $3.8 \%$, 
$6 \%$ and $8 \%$, all infections with Chlamydia trachomatis involvement ${ }^{6-8}$. C. trachomatis infection is the most prevalent sexually transmitted infection (STI) worldwide ${ }^{1}$. Considering that a large percentage of $C$. trachomatis infections are asymptomatic, many countries have established public health strategies for infection screening and control ${ }^{9,10}$.

Taking into consideration that the majority of studies were performed in symptomatic healthy women rather than in asymptomatic males with HIV, as we propose, persistent or recurrent urethritis due to chlamydial infection was reported in $13 \%$ of those assigned to standard partner referral treatment and $11 \%$ of those assigned to expedited treatment of sexual partners ${ }^{11}$. A two- to three-fold increased risk of chlamydial persistence or recurrence was observed among younger ( $=24$ years old) and white women reporting any of the following: a recent new partner, multiple partners, a partner who may have had multiple partners, or that not all partners were treated during the 1-month follow-up period after the initiation of treatment ${ }^{12,13}$. Another study indicated that reinfection was not clearly associated with having a new sex partner or other sexual behavior risks; new infection was likely due to the resumption of sex with untreated partners. Overall, $13.4 \%$ of women had persistent infections or became reinfected after a median of 4.3 months, a rate of 33 infections per 1,000 person-month ${ }^{14}$.

In a systematic review of chlamydial and gonococcal urethritis reinfection among men, recurrent chlamydia infection had a median of reinfection probability of $11.3 \%$. Recurrent gonorrhea infection among men had a median of reinfection probability of $7.0 \%$. Studies with active follow-up each 3-6 months had moderate rates of chlamydia and gonorrhea reinfection among men, with respective median rates of $10.9 \%$ and $7.0 \%$. Studies with passive follow-up varying from 30 days to 4.8 years had higher proportions of both chlamydia and gonorrhea reinfections among men, with respective medians of $17.4 \%$ and $8.5 \%$. Proportions of chlamydia and gonorrhea reinfection among men were comparable with those among women. Reinfection among men was strongly associated with a previous history of sexually transmitted diseases and younger age and was inconsistently associated with risky sexual behavior. Retesting recommendations in men are appropriate given the high rate of reinfection ${ }^{15}$.

This study aims to assess the recurrence of C. trachomatis urethritis three years after treatment in the same studied cohort and analyze the associated risk factors. To our knowledge, there are no other studies that evaluated this situation in patients living with HIV.

\section{MATERIALS AND METHODS}

\section{Patient recruitment}

In this prospective study, a total of 115 male patients were enrolled, including only those who were diagnosed with HIV infection and had no symptoms of urethritis or other STIs, aged 18 years or older, visiting the Immunology Outpatient Clinic of the Gaffree and Guinle University Hospital between May and August 2015. In the previous study in $2015^{1}$, we selected 111 patients (111/115) negative for asymptomatic urethritis and four patients (4/115) with asymptomatic urethritis due to $C$. trachomatis (prevalence $=3.47 \%$ ) who were treated together with their respective partners, and all of the subjects tested negative for urethritis one week later. We tested the 115 patients again three years later (February and March of 2018), searching for new prevalence data, recurrence or new cases of asymptomatic urethritis. All positive patients and their partners were treated or retreated with an oral, single dose of azithromycin (1 gram).

\section{Collection of demographic and clinical data}

This clinical and epidemiological study consisted of data collection from medical records and interview with the researcher responsible for data collection regarding: age, date of birth, place of residence, date of the first attendance, date of the first anti-HIV-1 positive test, ART treatment (yes or no), marital status, schooling (in years), sexual habits (sex with men and/ or women), sexual intercourse with multiple partners ( $\geq 3$ per year) use of antibiotic prophylaxis against pneumocystosis, neurotoxoplasmosis and Mycobacterium avium complex infections according to the $\mathrm{CD} 4^{+}$count, frequency of condom use, alcoholism (defined as the regular use of alcoholic beverages in quantities sufficient to cause significant social, interpersonal, family and/ or organic problems) and use of illicit drugs.

\section{Specimen collection and laboratory testing}

Urine samples were collected and tested by real-time PCR for the detection of C. trachomatis and $N$. gonorrhoeae (Abbott RealTime CT/NG test ${ }^{\circledR}$ ). Simultaneous blood collection was performed to obtain HIV viral load values (detection level of 40 copies $/ \mathrm{mL}$ ) and $\mathrm{CD} 4^{+} \mathrm{T}$ lymphocyte counts.

\section{Data analysis and statistical calculations}

The descriptive data analysis was performed by calculating the mean and standard deviation for continuous 
variables and the frequency of categorical variables. Associations between variables and the presence of asymptomatic urethritis, risks between variables and the development of recurrent asymptomatic urethritis were assessed by the chi-square test. Associations between categorical and continuous variables were assessed by analysis of variance followed by comparison of means by the Student t-test. A multivariate logistic regression analysis was performed using as covariables those that were statistically significant, binaries and categoricals, in order to identify variables independently associated with the diagnosis. Odds ratio $(\mathrm{OR})$ was used as a measure of association between an exposure and an outcome in the transversal analysis. Relative risk (RR) was used as a measure of risk or protection between an exposed in comparison to a non-exposed group in the prospective analysis. The level of statistical significance was set to $5 \%$. The programs $\operatorname{SPSS}^{\circledR} 17.0$ and Epi Info $7^{\circledR}$ were used for analyses.

\section{Ethics}

The study was evaluated and approved by the ethics committee of the University Hospital Gaffree and Guinle, under the $\mathrm{N}^{\circ}$ 02366912.1.0000.5248. All patients signed the informed consent forms, and the study followed all the guidelines for experimental investigation and ethical standards with human subjects required by the institution and the Helsinki Declaration.

\section{RESULTS}

\section{Patient recruitment and demographics}

The mean age of patients was 47.43 years, and the mean time of HIV diagnosis was 13.28 years. All $(100 \%)$ patients were using ART, and 15 patients (13\%) were under prophylaxis for opportunistic infections with trimethoprim/sulfamethoxazole alone (8 patients; $7 \%$ ) or associated with macrolide (7 patients; $6 \%$ ). The mean $\mathrm{CD} 4^{+} \mathrm{T}$ lymphocyte count for the subjects was 488 cells $/ \mathrm{mm}^{3}$, and $86 \%$ of patients had undetectable plasma HIV viral loads. Regarding lifestyle habits, $62 \%$ of the patients reported sexual practices with men, $72 \%$ had multiple partners ( $\geq 3$ per year) and $55 \%$ used condoms in sexual intercourse approximately $50 \%$ of the time.

\section{Prevalence of urethritis}

Three of the four patients (75\%) who had asymptomatic C. trachomatis urethritis in the previous study and were treated together with their partners in 2015 were recurrently positive for $C$. trachomatis urethritis. Two new patients were diagnosed as positive, accounting for a total C. trachomatis urethritis prevalence of $4.34 \%$ (five patients). Again, there were no cases of $N$. gonorrhoeae infection. The descriptions of cases are in Table 1 . The total number of asymptomatic urethritis cases detected during the study was six patients, with a prevalence of $5.21 \%$. Those who have previously had $C$. trachomatis asymptomatic urethritis presented forty-one times greater risk of developing a new urethritis episode three years later compared to those who did not have previous $C$. trachomatis asymptomatic urethritis $(\mathrm{RR}=41.62 ; 95 \% \mathrm{CI}: 9.42-183.84 ; \mathrm{p}<0.01)$.

\section{Risk factors}

Patients who presented with asymptomatic urethritis at any time and who were recurrently positive for C. trachomatis had a lower mean age $(\mathrm{p}<0.01)$.

We found associations with marital status, with married men having less risk of asymptomatic urethritis $[\mathrm{p}<0.01$, $\mathrm{OR}=0.04(0.005-0.4)]$, and with the use of illicit drugs increasing the risk for asymptomatic urethritis $[\mathrm{p}=0.02$, $\mathrm{OR}=5.9(1.03-34)]$.

Married men had 14\% less risk of developing recurrent asymptomatic urethritis $[\mathrm{p}<0.01, \mathrm{RR}=0.86(0.74-0.99)]$, and the use of ilicit drugs increased the risk of developing recurrent asymptomatic urethritis by $10 \%[\mathrm{p}<0.01, \mathrm{RR}=1.1$

Table 1 - Epidemiological data of the cases of asymptomatic urethritis detected during the study (with and without recurrence).

\begin{tabular}{lccccccccc}
\hline Case & $\begin{array}{c}\text { Previous CT } \\
\text { urethritis }\end{array}$ & $\begin{array}{c}\text { CT urethritis } \\
\text { detected }\end{array}$ & Age & Schooling & MSM & CD4/Viral Load & $\begin{array}{c}\text { Marital } \\
\text { status }\end{array}$ & Diagnostic & Drug use \\
\hline 1 & yes & yes & 28 & $<10 \mathrm{yr}$ & - & $212 /$ detected & Single & $6 \mathrm{yr}$ & yes \\
2 & yes & yes & 26 & $\geq 10 \mathrm{yr}$ & + & $178 /$ detected & Single & $6 \mathrm{yr}$ & yes \\
3 & yes & yes & 43 & $<10 \mathrm{yr}$ & + & $572 /$ undetected & Single & $7 \mathrm{yr}$ & yes \\
4 & yes & no & 41 & $\geq 10 \mathrm{yr}$ & - & $450 /$ undetected & Married & $11 \mathrm{yr}$ & no \\
5 & no & yes & 28 & $\geq 10 \mathrm{yr}$ & + & $141 /$ undetected & Single & $5 \mathrm{yr}$ & yes \\
6 & no & yes & 33 & $<10 \mathrm{yr}$ & + & $506 /$ undetected & Single & $5 \mathrm{yr}$ & no \\
\hline
\end{tabular}

CT:Chlamydia trachomatis, MSM - male who have sex with men 
(1.0-1.22)]. The descriptive analysis and associations between the group with and without urethritis and the risk analysis of recurrent urethritis are in Table 2.

To estimate adjusted OR and RR for factors associated with the presence of asymptomatic urethritis in the univariate analysis, a multivariate logistic regression analysis was performed. A model was created to include marital status and use of illicit drugs. The presence of asymptomatic urethritis was independently associated with marital status $[\mathrm{p}<0.01, \mathrm{OR}=0.1(0.01-0.3)]$, [p<0.01, $\mathrm{RR}=0.9(0.8-0.99)]$ and use of illicit drugs $[\mathrm{p}<0.05, \mathrm{OR}=4.2$ $(1.2-27)],[\mathrm{p}<0.01, \mathrm{RR}=1.2(1.0-1.3)]$.

\section{DISCUSSION}

A prevalence of $3.47 \%$ of asymptomatic urethritis has been previously reported in this studied sample, all cases caused by $C$. trachomatis, and three years later, the prevalence is $4.34 \%$. These data can be compared with studies in males living with HIV, as well as studies in the general population without HIV infection and other similar studies in different countries ${ }^{2-8}$.
The present study shows that a proportion of male patients living with HIV who have previously had asymptomatic urethritis and were treated for this condition, including their respective partners, have recurrence of infection three years later. All of them tested negative after the first antibiotic regimen against $C$. trachomatis three years earlier. We found recurrence among three of the four patients who had been previously infected (75\%). Recurrent symptomatic urethritis caused by chlamydia infection is reported at a prevalence of $13 \%{ }^{11}, 5.1 \%{ }^{12}$ and $4.1 \%^{13}$ among non-HIV-infected women and $11.3 \%$ among men ${ }^{15}$. There are no data on the recurrence of asymptomatic urethritis in males or females or among HIV patients.

Explanations for the high rate of recurrence in our study may be related to the follow-up period of three years, which is a long period of time to test recurrence when compared to the period of months investigated in previous studies of symptomatic urethritis ${ }^{15}$. Retesting of all chlamydia- and gonorrhea-infected men and women three months after the initial treatment is recommended by some groups ${ }^{15}$. Positive retesting for Chlamydia infection is more common among men who have sex with men (MSM) than among

Table 2 - Descriptive analysis and associations between the group with and without urethritis and risk analysis of recurrent urethritis $(\mathrm{N}=115)$.

\begin{tabular}{|c|c|c|c|c|c|c|c|c|c|}
\hline \multirow[t]{2}{*}{ Variables } & & \multirow{2}{*}{$\begin{array}{c}\text { Total } \\
(\mathrm{N}=115)\end{array}$} & \multirow{2}{*}{$\begin{array}{l}\text { No Urethritis } \\
(N=109)\end{array}$} & \multirow{2}{*}{$\begin{array}{c}\text { Recurrent } \\
\text { Urethritis } \\
(\mathrm{N}=3)\end{array}$} & \multirow{2}{*}{$\begin{array}{c}\text { Urethritis } \\
\text { Anytime } \\
(\mathrm{N}=6)\end{array}$} & \multicolumn{2}{|c|}{$\begin{array}{l}\text { Associations with } \\
\text { Urethritis at anytime }\end{array}$} & \multicolumn{2}{|c|}{$\begin{array}{c}\text { Risks of recurrent } \\
\text { Urethritis }\end{array}$} \\
\hline & & & & & & $P$ value & OR (Cl95) & $P$ value & $\mathrm{RR}(\mathrm{Cl} 95)$ \\
\hline Age (years) & & $47.43 \pm 10.6$ & $48.22 \pm 10.2$ & $32.33 \pm 9.2$ & $33.16 \pm 7.2$ & $<0.01^{*}$ & - & $<0.01^{*}$ & - \\
\hline \multirow{2}{*}{ Marital status } & Single & $25 / 115(22 \%)$ & $20 / 109(18 \%)$ & $3 / 3(100 \%)$ & $5 / 6(83 \%)$ & $<0.01^{*}$ & 0.04 & $<0.01^{*}$ & 0.86 \\
\hline & Married & $90 / 115$ (78\%) & $89 / 109(82 \%)$ & $0 / 3(0 \%)$ & $1 / 6(27 \%)$ & & $(0.005-0.4)$ & & $(0.74-0.99)$ \\
\hline \multirow{2}{*}{ Schooling } & $<10$ yrs & $32 / 115(28 \%)$ & $29 / 109(27 \%)$ & $2 / 3(66 \%)$ & $3 / 6(50 \%)$ & 0.13 & 0.36 & 0.1 & 0.94 \\
\hline & $\geq 10 \mathrm{yrs}$ & $83 / 115(72 \%)$ & $80 / 109(73 \%)$ & $1 / 3(34 \%)$ & $3 / 6(50 \%)$ & & $(0.07-1.9)$ & & $(0.86-1.04)$ \\
\hline $\begin{array}{l}\text { Time dia } \\
\text { (yrs) }\end{array}$ & & $13.28 \pm 7.4$ & $13.42 \pm 7.2$ & $6.33 \pm 5.7$ & $10.67 \pm 10.2$ & 0.37 & - & 0.1 & \\
\hline \multirow{2}{*}{ Prophylaxis } & No & $100 / 115(87 \%)$ & $96 / 109$ (24\%) & $2 / 3(66 \%)$ & $4 / 6(66 \%)$ & 0.1 & 3.7 & 0.2 & 1.05 \\
\hline & Yes & $15 / 115(13 \%)$ & $13 / 109(76 \%)$ & $1 / 3(34 \%)$ & $2 / 6(34 \%)$ & & $(0.6-22.2)$ & & $(0.9-1.2)$ \\
\hline \multirow{2}{*}{$\begin{array}{l}\text { Sexual behavior } \\
\text { (MSM) }\end{array}$} & No & 44/115 (38\%) & 42/109 (39\%) & 1/3 (34\%) & $2 / 6(34 \%)$ & 0.41 & 1.25 & 0.4 & 1.0 \\
\hline & Yes & $71 / 115(62 \%)$ & $67 / 109(61 \%)$ & $2 / 3(66 \%)$ & $4 / 6(66 \%)$ & & $(0.22-7.1)$ & & $(0.94-1.06)$ \\
\hline \multirow{2}{*}{ Multiple Partners } & No & $31 / 115(27 \%)$ & $30 / 109(28 \%)$ & $1 / 3(34 \%)$ & $1 / 6(17 \%)$ & 0.31 & 1.9 & 0.4 & 0.99 \\
\hline & Yes & $84 / 115(73 \%)$ & 79/109 (72\%) & $2 / 3(66 \%)$ & $5 / 6(83 \%)$ & & $(0.21-17)$ & & $(0.92-1.06)$ \\
\hline \multirow{2}{*}{ Condom } & $<50 \%$ & $52 / 115(45 \%)$ & $49 / 109(45 \%)$ & $2 / 3(66 \%)$ & $3 / 6(50 \%)$ & 0.40 & 0.81 & 0.2 & 0.97 \\
\hline & $\geq 50 \%$ & $63 / 115(55 \%)$ & $60 / 109(55 \%)$ & $1 / 3(34 \%)$ & $3 / 6(50 \%)$ & & $(0.15-4)$ & & $(0.91-1.04)$ \\
\hline \multirow{2}{*}{ Alcoholism } & No & $104 / 115(90 \%)$ & $100 / 109(92 \%)$ & $2 / 3(66 \%)$ & $4 / 6(\%)$ & 0.05 & 5.55 & 0.1 & 1.08 \\
\hline & Yes & $11 / 115(10 \%)$ & $9 / 109(8 \%)$ & $1 / 3(34 \%)$ & 2/6 (\%) & & $(0.9-34.6)$ & & $(0.88-1.34)$ \\
\hline \multirow{2}{*}{ Illicit drug use } & No & $84 / 115(73 \%)$ & $89 / 109$ (82\%) & $0 / 3(0 \%)$ & $2 / 6(34 \%)$ & $0.02^{*}$ & 5.9 & $<0.01^{*}$ & 1.1 \\
\hline & Yes & $31 / 115(27 \%)$ & $30 / 109(18 \%)$ & $3 / 3(100 \%)$ & $4 / 6(66 \%)$ & & $(1.03-34)$ & & $(1.0-1.22)$ \\
\hline $\mathrm{CD4}^{+}\left(\right.$cells/mm $\left.{ }^{3}\right)$ & & $488 \pm 309$ & $492 \pm 315$ & $320 \pm 218$ & $413 \pm 175$ & 0.54 & & 0.34 & \\
\hline \multirow{2}{*}{ Viral load } & $\leq 40 / \mathrm{mL}$ & $99 / 115(86 \%)$ & $85 / 109(78 \%)$ & $2 / 3(66 \%)$ & $4 / 6(66 \%)$ & 0.26 & 1.77 & 0.32 & 1.01 \\
\hline & $>40 / \mathrm{mL}$ & $16 / 115(14 \%)$ & $24 / 109(22 \%)$ & $1 / 3(34 \%)$ & $2 / 6(34 \%)$ & & $(0.3-10)$ & & $(0.93-1.1)$ \\
\hline $\begin{array}{l}\text { Asymptomatic } \\
\text { drethritis }\end{array}$ & & - & $94,8 \%$ & $2,6 \%$ & $\begin{array}{c}5,21 \% \\
(4,34 \%)^{\star *}\end{array}$ & & & & \\
\hline
\end{tabular}

SD - standard deviation. * $(p<0.05) .{ }^{* \star}$ Prevalence in this study. 
heterosexuals and treatment failure is more common in $\mathrm{MSM}^{15}$. Other possible reasons are as follows: the focus on studying asymptomatic cases; the population profile (MSM living with HIV, most of them with multiple partners, using condoms in sexual intercourse less than $50 \%$ of the time). These risk factors were analyzed but results were not statistically significant. However, the absence of evidence does not mean evidence of absence, and a larger sample size could influence these results. Other studies suggest that reinfection among men can be related to a previous history of sexually transmitted diseases as well as younger age and is associated with risky sexual behavior ${ }^{15}$. Because all of the recurrence cases tested negative after their first treatment three years ago, the new infections were likely to be due to resumption of sex with untreated partners.

In our sample, patients who presented with asymptomatic urethritis at any time and who were recurrently positive for C. trachomatis had a lower mean age, consistent with the literature already presented ${ }^{12,13,15}$. The age factor may be related to a greater frequency of sexual intercourse or exposure to multiple partners. Similarly, less exposure to multiple partners can also explain the protective effect of marriage with respect to the prevalence of asymptomatic urethritis and the development of recurrent asymptomatic urethritis. The use of illicit drugs increasing the risk for asymptomatic urethritis and the development of recurrent asymptomatic urethritis can be explained by negligent behavior (e.g., sexual intercourse with multiple partners or negligent condom use) and even by non-trustworthy reporting or memory bias in sexual behavior questions.

This study has limitations related to the small sample size combined with the small prevalence of asymptomatic urethritis. On the other hand, a prospective evaluation including treatment of positive patients and partners and sequential retesting (after treatment and three years later) can contribute to the understanding of the natural history of the development and recurrence of asymptomatic urethritis and risk factors associated with this condition. This study argues for retesting.

\section{REFERENCES}

1. Silva GA, Motta HL, Souza EF, Cardoso PA, Pilotto JH, EyerSilva WA, et al. Prevalence of asymptomatic urethritis by Chlamydia trachomatis and Neisseria gonorrhoeae and associated risk factors among males living with HIV-1. Rev Inst Med Trop São Paulo. 2018;60:e11.

2. Fioravante FC, Alves MF, Guimarães EM, Turchi MD, Freitas HA, Domingos LT. Prevalence of Chlamydia trachomatis in asymptomatic Brazilian military conscripts. Sex Transm Dis. 2005;32:165-9.
3. Gillespie CW, Manhart LE, Lowens MS, Golden MR. Asymptomatic urethritis is common and is associated with characteristics that suggest sexually transmitted etiology. Sex Transm Dis. 2013;40:271-4.

4. Miller WC, Ford CA, Morris M, Handcock MS, Schmitz JL, Hobbs MM, et al. Prevalence of chlamydial and gonococcal infections among young adults in the United States. JAMA. 2004;291:2229-36.

5. Cohen DA, Nsuami M, Etame RB, Tropez-Sims S, Abdalian S, Farley TA, et al. A school-based Chlamydia control program using DNA amplification technology. Pediatrics.1998;101:E1.

6. Winter AJ, Taylor S, Workman J, White D, Ross JD, Swan AV, et al. Asymptomatic urethritis and detection of HIV-1 RNA in seminal plasma. Sex Transm Infect. 1999;75:261-3.

7. Lewis DA, Chirwa TF, Msimang VM, Radebe FM, Kamb ML, Firnhaber CS. Urethritis/cervicitis pathogen prevalenceand associated risk factors among asymptomatic HIV-infected patients in South Africa. Sex Transm Dis. 2012;39:531-6.

8. Farley TA, Cohen DA, Wu SY, Besch CL. The value of screening for sexually transmitted diseases in an HIV clinic. J Acquir Immun Defic Syndr. 2003;33:642-8.

9. Nelson HD, Helfand M. Screening for chlamydial infection. Am J Prev Med. 2001;20:95-107.

10. Golden MR, Whittington WL, Handsfield HH, Hughes JP, Stamm WE, Hogben M, et al. Effect of expedited treatment of sex partners on recurrent or persistent gonorrhea or chlamydial infection. N Engl J Med. 2005;352:676-85.

11. Hillis SD, Coles FB, Litchfield B, Black CM, Mojica B, Schmitt $\mathrm{K}$, et al. Doxycycline and azithromycin for prevention of chlamydial persistence or recurrence one month after treatment in women: a use-effectiveness study in public health settings. Sex Transm Dis.1998;25:5-11.

12. Hillis SD, Nakashima A, Marchbanks PA, Addiss DG, Davis JP. Risk factors for recurrent Chlamydia trachomatis infections in women. Am J Obstet Gynecol. 1994;170:801-6.

13. Whittington WL, Kent C, Kissinger P, Oh MK, Fortenberry JD, Hillis SE, et al. Determinants of persistent and recurrent Chlamydia trachomatis infection in young women: results of a multicenter cohort study. Sex Transm Dis. 2001;28:117-23.

14. Fung M, Scott KC, Kent CK, Klausner JD. Chlamydial and gonococcal reinfection among men: a systematic review of data to evaluate the need for retesting. Sex Transm Infect. 2007;83:304-9.

15. Smith KS, Guy R, Danielewski J, Tabrizi SN, Fairley CK, McNulty AM, et al. Biological and behavioral factors associated with positive Chlamydia retests. Sex Transm Dis. 2017;44:417-22. 